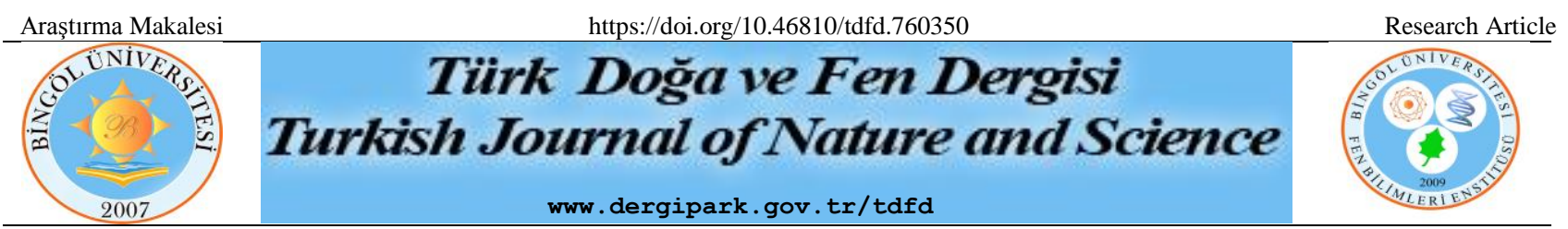

\title{
Lavantada Köklenme Üzerine Çelik Kalınlıklarının Etkisi
}

\author{
Nimet KARA $^{1 *}$, Hasan BAYDAR ${ }^{1}$ \\ ${ }^{1}$ Isparta Uygulamamalı Bilimler Üniversitesi Ziraat Fakültesi Tarla Bitkileri Bölümü, Isparta, Türkiye \\ Nimet KARA ORCID No: 0000-0001-7069-0877 \\ Hasan BAYDAR ORCID No: 0000-0003-1317-2066
}

*Sorumlu yazar: nimetkara@isparta.edu.tr

(Alınış: 29.06.2020, Kabul: 14.10.2020, Online Yayınlanma: 23.10.2020)

\begin{abstract}
Anahtar Kelimeler Lavanta, Çelik kalınlığı, Köklenme oran1

Öz: Araştırma, Lavandula angustifolia var. Raya ve Lavandula x intermedia var. Super çeşitlerinin yaklaşık $15 \mathrm{~cm}$ uzunluğunda 2,0-3,0, 3,1-4,0, 4,1-5,0, 5,1-6,0 ve 6,1 mm üzeri olarak sınıflandırılan beş farklı kalınlıktaki çelikler kullanılarak, köklenme oranı, kök uzunluğu ve kök sayısına etkisini incelemek amacıyla tesadüf parselleri deneme desenine göre üç tekerrürlü olarak yürütülmüştür. Köklenme oranı, kök sayısı ve kök uzunluğu bakımından çeşitler ve çelik kalınlıkları arasındaki farklar istatistiksel olarak önemli çıkmış ve Raya çeşidinin köklenme özellikleri Super çeşidinden daha yüksek olmuştur. Çelik kalınlıklarına bağlı olarak köklenme oranı, kök sayısı ve uzunluğunda belirgin bir artış veya azalış göstermemiş, ancak köklenme değerleri 3,1-4,0 mm kalınlığındaki çeliklerde daha yüksek olmuştur. Sonuç olarak, lavantada köklenme için en uygun çelik kalınlığı 3,1-4,0 mm olarak belirlenmiştir.
\end{abstract}

Effect of Cuttings Thicknesses on Rooting in Lavender

\begin{abstract}
Keywords Lavender, Cutting thicknesses, Rooting rate
\end{abstract}

\section{GíRiş}

Lavandula sp, Lamiaceae familyasından yarı çalımsı formda, çok yıllık, değerli bir uçucu yă̆ bitkidir. Lavantanın, taze veya kuru saplı çiçeklerinden elde edilen uçucu yağından, kurutma sonrasında saplarında ayrılan tomurcuklarından ve kuru demet çiçek şeklinde vazo bitkisi olarak faydalanılmaktadır. Lavantanın özellikle antimikrobiyal, antibakteriyel, antivirütik ve antioksidan etkisinin olması ve hoş kokuya sahip olması nedeniyle gıda katkısı, kozmetik, parfümeri, ilaç, aromaterapi gibi pek kullanım alanına sahiptir. Lavantanın iklim ve toprak isteğinin çok yüksek olmaması, bakım işlemlerinin kolay olması ve kullanım alanlarının giderek artması, lavanta tarımına ilgiyi arttımış ve üretim alanları geniş̧lemiştir [1].

Lavanta bitkisi diğer aromatik bitkilerde olduğu gibi üretimi ve çoğaltılması generatif ve vejetatif olarak başlıca iki yolla gerçekleştirilir. Bazı lavanta türleri sadece generatif olarak tohumlarıla, bazı türleri ise vejetatif olarak sürgün çelikleri ile bazı lavanta tür ve çeşitleri ise her iki yolla daha kolay ve hızlı bir şekilde çoğaltılabilmektedir. Lavanta (Lavandula sp.) türleri arasında uçucu yağ üretiminde kullanılan en önemli iki tür lavander (L. angustifolia Mill., syn. L. officinalis, $L$. vera) ve lavandin (L.x intermedia Emeic ex Loisel., syn. L. hybrida)'dir. Lavander (L. angustifolia $=$ L. officinalis $=L$. vera) çeşitleri hem generatif hem de vejetatif olarak çoğaltılabilirken, L. angustifolia ve L. latifolia melezi olan lavandin (L.x intermedia $=$ L. hybrida) çeşitleri kısır 
olduklarından tohum üretemezler ve bu nedenle vejetatif olarak çoğaltılabilmektedir [1]. Tıbbi ve aromatik bitkilerde genel olarak tek yıllık ve otsu yapıda olan türler tohumlarıyla genaratif olarak, çok yıllık ve odunsu olanlar ise yaygın olarak vejatatif olarak çoğaltılırlar. Çelikle çoğaltma basit ve kolay uygulanabilir olması, birim alandan çok sayıda fidan elde edilmesi [2], anaç bitkiyle aynı genetik yapıya sahip ve kaliteli fidan elde edilmesi gibi avantajlarından dolayı birçok bitkinin çoğaltılmasında yaygın olarak kullanılan bir yöntemdir. Çelikle üretimde köklenme başarısı bitki türü, anaç bitkinin yaşı, çelik alma zamanı, çelik tipi ile kullanılan bitki büyüme düzenleyiciler, köklendirme ortamları ve çevre koşulları gibi birçok faktöre bağlı olarak değişmektedir [3]. Farklı bitki türlerinde yürütülen çalışmalarda köklenmenin türlere ve çelik kalınlıklarına göre değiştĭgi $[4,5]$ rapor edilmiştir. Özellikle çelik alımında belirli kalınlıkta ve gözlere sahip çelikler avantaj oluştururken, diğer taraftan anaç bitki yetersizliği en önemli dezavantajı oluşturmaktadır. Tohum üretmeyen ve anaç bitkinin yetersiz olduğu durumlarda, yeterli fide elde etmek için, olabildiğince fazla sayıda çelik elde edilmesi önem taşımaktadır. Araştırma, lavantada farklı kalınlıklara sahip dalların (çeliklerin) köklenme özelliklerinin incelenmesi amaciyla yürütülmüştür.

\section{MATERYAL VE METOT}

Araştırma Isparta Uygulamalı Bilimler Üniversitesi Ziraat Fakültesi Tarla Bitkileri Bölümüne ait serada 2019 y1lında yürütülmüştür. Tarla Bitkileri Bölümü deneme arazisinde yetiştirilen $L$. angustifolia var. Raya ve Lavandula $\mathrm{x}$ intermedia var. Super çeşitlerine ait anaç bitkilerinin çelikleri materyal olarak kullanılmıştır. Her iki çeşitten Mart ayında yaklaşı $15 \mathrm{~cm}$ uzunluğunda kumpas ile ölçülerek 2,0-3,0, 3,1-4,0, 4,1-5,0, 5,1-6,0 ve $6,1 \mathrm{~mm}$ üzeri olarak sınıflandırılan beş farklı kalınlıkta 60 'şar adet çelik hazırlanmıştır. Deneme tesadüf parselleri deneme desenine göre üç tekerrürlü olarak, her tekerrürde 20 adet çelik olacak şekilde kurulmuştur. Köklendirme hormonu olarak Indol-3 bütrik asitin (IBA) 4000 ppm'lik konsantrasyonuna çeliklerin yaklaşı 3-4 $\mathrm{cm}$ alt kısımları hızlı daldırma yöntemine göre 5 saniye süreyle daldırıldıktan sonra [6], sera ortamında perlit ve torftan (1:1) oluşan köklendirme kasalarına dikilmiş ve otomatik sisleme ile düzenli olarak sulanmıştır. Çelikler sera ortamında 60 gün bekletilmiş ve köklenen çelikler sayılarak köklenme oranı (\%) tespit edilmiştir. Ayrıca köklenen çeliklerde ortalama kök sayısı (adet/çelik) ve ortalama kök uzunluğu ( $\mathrm{cm} / \mathrm{kök})$ belirlenmiştir. Elde edilen verilerin varyans analizi JUMP 5.0 istatistik programı kullanılarak yapılmış ve ortalamalar arasındaki farklar DUNCAN testine göre karşılaştırılmıştır.

\section{BULGULAR VE TARTIŞMA}

Lavanta çeşitlerine ait çeliklerin köklenme oranı, kök sayısı ve kök uzunlukları arasındaki farklılıklar istatistiksel olarak $\mathrm{P} \leq 0.01$ düzeyinde önemli olmuştur. Raya çeşidinin köklenme oranı $(\% 47,1)$, kök sayısı $(5,5$ adet/çelik) ve kök uzunluğu $(3,16 \mathrm{~cm})$, Super çeşidinden (sırasıyla, \%40,6, 3,7 adet/çelik ve 1,85 cm) daha yüksek oluştur (Tablo 1).

Çelik kalınlıklarının köklenme oranı, kök sayısı ve uzunlukları arasındaki farklar istatiksel olarak önemli olmuş, en yüksek köklenme oranı ve kök sayısı 3,1-4,0 $\mathrm{mm}$ kalınlığındaki (sırasıyla, \%59,0 ve 5,4 adet/çelik) çeliklerde ve en yüksek kök uzunluğu 2,91 cm ile 2,0-3,0 mm kalınlığındaki çeliklerde belirlenmiştir. En düşük kökleme oranı $(\% 33,0)$ ve kök sayısı $(3,4$ adet/çelik) en ince çelik sınıfinda (2,0-3,0 mm) ölçülürken, en kısa kök uzunluğu $2,08 \mathrm{~cm}$ ile $4,1-5,0 \mathrm{~mm}$ çelik kalınlığında belirlenmiştir (Tablo 1).

Çeşit x çelik kalınlığ kombinasyonu incelendiğinde, en yüksek köklenme oranı $(\% 66,2)$ ve kök sayısı $(7,1$ adet/(çelik) Raya çeşidinin 3,1-4,0 mm çelik kalınlığında belirlenirken, en yüksek kök uzunluğu $3,93 \mathrm{~cm}$ ile yine Raya çeşidinin 2,0-3,0 $\mathrm{mm}$ çelik kalınlığında ölçülmüştür. En düşük köklenme oranı $(\% 30,6)$ ve kök sayısı (2,9 adet/çelik) Super çeşidinin 2,0-3,0 mm kalınlığındaki çeliklerde ölçülmüş ve en kısa kök uzunluğu 1,61 cm ile yine Super çeşidinin 5,1-6,0 mm kalınlığındaki çeliklerden elde edilmiştir (Tablo 1).

Bir lavander çeşidi olan Raya'nın köklenme özellikleri, Super lavandin çeşidine göre daha yüksek olmuştur. Sürgün çeliklerinde adventif kökler iletim kambiyum dokusundan meydana gelmektedir. Kambiyum dokusunun kalınlığ 1 ve meristamatik aktivitesi köklenme başarısı üzerine doğrudan etkili olduğu bilinmektedir. Kambiyumdan kök oluşumunu teşvik etmek için başta IBA olmak üzere, oksin gurubu hormon uygulamaları yapılmaktadır. $\mathrm{Bu}$ araştırmada lavender çeliklerinin lavandin çeşidine göre iletim kabuğunun aktivitesinin daha fazla olduğu veya oksin hormonlarının adventif kök oluşumuna daha iyi reaksiyon gösterdiğini ortaya koymaktadır. Bulgularımıza benzer şekilde Kara [6] genel olarak lavender çeşitlerinin köklenme özelliklerinin lavandin çeşitlerine göre daha iyi olduğunu bildirmiştir. Çelik kalınlıklarına bağlı olarak köklenme özelliklerinde anlamlı bir artış ya da düşüş olmamış, ancak aralarındaki farklılık önemli çıkmıştır. Genellikle en yüksek köklenme değerleri $3,1-4,0 \mathrm{~mm}$ olan orta kalınlıktaki çeliklerde belirlenmiştir. Genel olarak kök sayısı ile kök uzunluğu arasında olumsuz bir ilişki olduğu, kök sayısı az olan çeliklerde kök uzunluğunun daha fazla olduğu gözlemlenmiş̧tir (Tablo 1).

Farklı bitki türlerinin (asma, sardunya, Norveç çamı) çelikle çoğaltımı üzerine yapılan araştırmalarda genellikle orta ve kalın çeliklerin daha yüksek köklenme değerlerine sahip oldukları bildirilmiştir $[4,5,7]$. Bunun nedeninin çelikler kalınlaştıkça köklenmeyi teşvik eden oksin hormonun yükseldiğini [8] ve karbonhidrat miktarının daha fazla olduğu [9] ifade edilmektedir. Bu görüşün aksine, Goodin [10] daha az lifli veya lifsiz olan genç sürgünlerin daha iyi köklendiğini bildirmiştir. Hedge [11] fenol bileşikler, azot ve nişasta içeriklerinin bitkinin morfolojik yapısına bağlı olarak değiştiği ve bunun bitkinin farklı kısımlarından üretilen çeliklerin köklenme kabiliyetlerinin değişmesine neden olduğunu rapor etmiş̧ir. Rana [12] ve Swetha [13] karbonhidrat ve 
fenolikler ile köklenme arasında pozitif ilişki, azot içeriği ile negatif bir ilişskinin olduğunu ve bu bileşikler çeliklerin fizyolojik durumlarına, sürgün ve kök gelişimi üzerine kuvvetli etki yaptığını bildirmişlerdir. Bunların yanında, çeliklerin köklenme oranları arasında farklılıkların türlerin regenerasyon yeteneklerine ve genetik yapılarına, uygun ortam koşullarına, anaç bitkinin yaşına, çelik uzunluğuna, ana bitkinin hormonal seviyesine ve anatomik yapısına göre değiştiği bildirilmiştir [14, 15, 16, 17].

Tablo 1. Lavanta çeliklerinin köklenme oranı, kök sayısı ve uzunluğuna çelik kalınlığının etkisi

\begin{tabular}{|c|c|c|c|c|}
\hline Çeşitler & Çelik kalınlığ $(\mathrm{mm})$ & Köklenme oranı (\%) & Kök sayısı (adet/çelik) & Kök uzunluğu $(\mathrm{cm})$ \\
\hline \multirow{5}{*}{$\begin{array}{l}\text { L. angustifolia var. } \\
\text { Raya }\end{array}$} & $2,0-3,0$ & $36,5 \mathrm{e}$ & $3,8 \mathrm{dc}$ & $3.93 \mathrm{a}$ \\
\hline & $3,1-4,0$ & $66,2 \mathrm{a}$ & $7,1 \mathrm{a}$ & $3.31 \mathrm{~b}$ \\
\hline & $4,1-5,0$ & $47,6 \mathrm{bc}$ & $5,9 \mathrm{~b}$ & $2.34 \mathrm{c}$ \\
\hline & $5,1-6,0$ & $46,3 \mathrm{bc}$ & $4,6 \mathrm{c}$ & $3.46 \mathrm{~b}$ \\
\hline & 6,1 üzeri & $40,1 \mathrm{~d}$ & $6,1 \mathrm{~b}$ & $2.77 \mathrm{~d}$ \\
\hline \multirow{6}{*}{$\begin{array}{l}\text { L.x intermedia var. } \\
\text { Super }\end{array}$} & $2,0-3,0$ & $30,6 \mathrm{f}$ & $2,9 \mathrm{e}$ & $1.90 \mathrm{f}$ \\
\hline & $3,1-4,0$ & $52,4 \mathrm{~b}$ & $3,6 \mathrm{~d}$ & $2.27 \mathrm{e}$ \\
\hline & $4,1-5,0$ & $45,3 \mathrm{c}$ & $3,3 \mathrm{e}$ & $1.72 \mathrm{f}$ \\
\hline & $5,1-6,0$ & $41,0 \mathrm{~d}$ & $4,4 \mathrm{c}$ & $1.61 \mathrm{f}$ \\
\hline & 6,1 üzeri & $35,2 \mathrm{e}$ & $4,1 \mathrm{c}$ & $1.87 \mathrm{f}$ \\
\hline & ÇxÇK & $21,92 * *$ & $9,45 * *$ & $6,26^{*}$ \\
\hline \multirow{3}{*}{ Çeşitler } & Raya & $47,1 \mathrm{~A}$ & $5,5 \mathrm{~A}$ & $3.16 \mathrm{~A}$ \\
\hline & Süper & $40,6 \mathrm{~B}$ & $3,7 \mathrm{~B}$ & $1.85 \mathrm{~B}$ \\
\hline & $i_{\text {Ceşit }}$ & $21,61 * *$ & $91,50 * *$ & $54,96 * *$ \\
\hline \multirow{5}{*}{ Çelik kalınlığı } & $2,0-3,0$ & $33,0 \mathrm{C}$ & $3,4 \mathrm{C}$ & $2.91 \mathrm{~A}$ \\
\hline & $3,1-4,0$ & $59,0 \mathrm{~A}$ & $5,4 \mathrm{~A}$ & $2.79 \mathrm{AB}$ \\
\hline & $4,1-5,0$ & $46,3 \mathrm{~B}$ & $4,6 \mathrm{~B}$ & $2.08 \mathrm{C}$ \\
\hline & $5,1-6,0$ & $43,5 \mathrm{~B}$ & $4,5 \mathrm{~B}$ & $2.54 \mathrm{ABC}$ \\
\hline & 6,1 üzeri & $37,5 \mathrm{C}$ & $5,1 \mathrm{AB}$ & $2.32 \mathrm{BC}$ \\
\hline \multicolumn{2}{|c|}{ F değeri Celik kalınlığı } & $39,89 * *$ & $12,23 * *$ & $5,59 *$ \\
\hline \multicolumn{2}{|c|}{ VK $(\%)$} & 8,77 & 11,69 & 9,20 \\
\hline
\end{tabular}

*, **: Sirasiyla $\mathrm{P} \leq 0,05$ ve $\mathrm{P} \leq 0,01$ düzeyinde önemli

Aynı sütunda benzer harfler ile gösterilen ortalamalar arasında istatistiksel olarak fark yoktur

\section{SONUÇ}

Çeşitler ve çelik kalınlıkları birlikte değerlendirildiğinde, her iki lavanta çeşidinde ve tüm çelik kalınlılarında değişik oranlarda köklenme olmuş, fakat köklenme oranı, kök sayısı ve uzunluğu çeşitlere ve çelik kalınlıklarına göre değişmiştir. Raya'nın köklenme kabiliyeti Super çeşidinden daha yüksek olmuştur. İncelenen köklenme özellikleri çelik kalınlıklarına bağlı olarak belirgin bir artıs veya azalıs göstermemiştir, ancak genel olarak 3,1-4,0 mm çelik kalınlığında daha yüksek değerler tespit edilmiştir. Sonuç olarak, lavantada kalınlıklarına göre sınıflandırılan tüm çeliklerin fide elde etmek amacıyla kullanılabileceği, ancak köklenme için en uygun çelik kalınlığının 3,1-4,0 mm olduğu belirlenmiş ve önerilebilir bulunmuştur.

\section{KAYNAKLAR}

[1] Kara N, Baydar H. Determination of lavender and lavandin cultivars (Lavandula sp.) containing high quality essential oil in Isparta, Turkey. Turk $\mathbf{J}$ of Field Crops. 2013; 18(1): 58-65.

[2] Alp Ş, Yıldız K, Türkoğlu N, Çiğ A, Aşur F. Van ilindeki eski bahçe güllerinin değişik çelik tipleri ile çoğaltılması. YYÜ Tarım Bilim Der. 2010; 20(3): 189-193.

[3] Sarı Y, Kaçar O. Biberiye (Rosmarinus officinalis L.) çeliklerinde köklenme üzerine farklı köklendirme ortamları ve IBA dozlarının etkileri. Bahçe. 2019; 48(1): 27-37.
[4] Doğan A, Uyak C, Kazankaya A. Effects of indolebutyric acid doses, different rooting media and cutting thicknesses on rooting ratios and root qualities of 41B, 5BB and 420A American grapevine rootstocks. J Applied Bio Sci. 2016; 10(2): 8-15.

[5] Al-Abbasi AM. Effect of cutting length and thickness on rooting of Geranium plant Pelargonium hortorum cuttings in Basrah City. Basra Studies J. 2012; 14: 1-10.

[6] Kara N. Uçucu Yağ üretimine uygun lavanta (Lavandula sp.) çeşitlerinin belirlenmesi ve mikroçoğaltım olanaklarının araştırılması. Süleyman Demirel Üni. Fen Bilimleri Enstitüsü, Tarla Bitkileri Anabilim Dalı, Doktora Tezi, 161s., 2011.

[7] Yang FO, Wang J, Li Y. Effects of cutting size and exogenous hormone treatment on rooting of shoot cuttings in Norway spruce [Picea abies (L.) Karst.]. New Forests. 2015; 46: 91-105. doi:10.1007/s11056-014-9449-1

[8] Palanisamy K, Kumar P. Effect of position, size of cuttings and environmental factors on adventitious rooting in neem (Azadirachta indica A. Juss). For Ecol Manag. 1997; 98(3): 277-280.

[9] Tchoundjeu Z, Leakey R. Vegetative propagation of African mahogany: effects of auxin, node position, leaf area and cutting length. New For. 1996; 11(2): 125-136.

[10] Goodin JR. Biochimical and morphological changes associatedwith juvenile and natura phases 
in hadera. Ph. Dr. Thesis, California Univ. Los Angeles, California; 1962.

[11] Hedge SS. Propagation studies in some ornamental shrubs by cuttings. Sc. (Agri.) Thesis, University of Agricultural Sciences, Dharwad; 1988.

[12] Rana HS. Mist propagation of plum clonal root stocks by stem-cuttings and their relationship with some biochemical constituents. Advances in Horticul and For. 1996; 5: 61-68.

[13] Swetha H. Propagation of Indian lavender (Bursera delpechiana poiss. Ex Engl.) thorugh cuttıngs under mist. Master Thesis, Department of Horticulture College of Agriculture, Dharwad University of Agricultural Sciences, Dharwad-580 $005 ; 2005$.

[14] Gil-Albert F, Boix E. Effects of treatment with IBA on rooting of Ornamenta conifers. Acta Horticul. 1978; 79: 63-77.

[15] Hartmann HT, Kester DE, Davies F, Geneve YR. Plant propagation: Principles and practices. $6^{\text {th }}$ ed. Prentice-Hall, Upper Saddle River. New Jersey; 1997. p.770.

[16] Schaberg PG, Snyder MC, Shane JB, Donnelly JR. Seasonal patterns of carbohydrate reserves in red spruce seedlings. Tree Physiol. 2000; 20: 549-555.

[17] Ahmed M, Laghari MH, Ahmed I, Khokhar KM. Seasonal variation in rooting of leafy olive cuttings. Asian J of Plant Sci. 2002; 1(3): 228-229. 